\title{
Environmental anti-androgens and male reproductive health: focus on phthalates and testicular dysgenesis syndrome
}

\author{
Jane S Fisher \\ The University of London, School of Pharmacy, Department of Toxicology, 29-39 Brunswick Square, London, \\ WC1N 1AX, UK \\ Correspondence should be addressed to Jane S Fisher; Email: jane.fisher@ulsop.ac.uk
}

\begin{abstract}
The amount of research into endocrine disruption has exploded over the past decade and a re-evaluation of the state of research in this area is timely. There are debates about whether human male reproductive health is really declining and whether endocrine disrupting chemicals play any role in the perceived decline. Most data currently conclude that there are wide geographical variations in semen quality and in the incidence of testicular cancer, cryptorchidism and hypospadias. This review aims to give a brief overview of the issues surrounding the perceived decline in human male reproductive health and the importance of the hormonal environment for the development of the testis and reproductive tract. The consequences for the male reproductive tract of abnormal androgen levels or action are discussed with reference to environmental anti-androgenic compounds. The in vivo data on several anti-androgenic compounds that have been administered to pregnant rodents during the period of male reproductive tract development are assessed with attention to the effects on the male offspring. Finally, the data on in utero phthalate administration are discussed in detail to illustrate the similarities between the effects of some phthalate esters and the human male reproductive tract disorders which comprise testicular dysgenesis syndrome (TDS). Reproduction (2004) 127 305-315
\end{abstract}

\section{Introduction}

The phrase 'endocrine disruption' has seemingly become inextricably linked with terms like 'environmental oestrogens' and 'falling sperm counts'. While these connections aid understanding about these issues, they represent a simplified view of the field of endocrine disruption. An 'endocrine disruptor' is anything (not just an environmental chemical) which can cause an imbalance within the endocrine system. The endocrine system is not only concerned with the reproductive tract, but with all the hormone-producing organs/glands which maintain bodily homeostasis (e.g. thyroid, parathyroids, anterior and posterior pituitary, pancreas, adrenals, pineal, and the gonads (IPCS 2002).

The endocrine system can be regarded as a number of interconnecting and interacting axes. The major regulator of the mature reproductive system is the hypothalamopituitary-gonadal (HPG) axis that functions as a classical negative feedback system. This consists of the gonadotrophin-releasing hormone $(\mathrm{GnRH})$ neurons in the hypothalamus (brain) that release $\mathrm{GnRH}$ into the portal blood supply. GnRH stimulates the release of gonadotrophins (luteinising hormone (LH) and follicle-stimulating hormone $(\mathrm{FSH})$ ) from the gonadotroph cells in the pituitary gland. $\mathrm{LH}$ and $\mathrm{FSH}$ travel through the systemic circulation and act on the endocrine active cells of gonad (testis or ovary). Within the testis, the Leydig cells secrete testosterone and oestradiol and the Sertoli cells secrete inhibin B. These gonadal signals feedback to the pituitary and hypothalamus to regulate the release of $\mathrm{GnRH}$ and the gonadotrophins (IPCS 2002). There is the potential for endocrine disrupting chemicals (EDCs) to act at any level of the HPG axis but there is general support for the view that the development and programming of the axis during fetal life could be the most sensitive window to permanently alter the homeostatic mechanisms of the endocrine system (IPCS 2002).

There is currently no strong data to suggest that environmental EDCs are responsible for the observed degeneration in human male reproductive health, but there are secular trends to suggest that it is declining. There is, however, very good evidence that lifestyle factors (e.g. smoking and/or alcohol consumption) can have an impact on fertility (Sharpe \& Franks 2002). Similarly, the notion that all EDCs act by mimicking oestrogen (environmental oestrogens) is too simplistic. The current literature illustrates 
that EDCs can act as oestrogens, anti-oestrogens, antiandrogens, steroidogenic enzyme inhibitors and can also act via interaction with the thyroid hormones and their receptors, or within the brain and the hypothalamo-pituitary axis, as well as the immune system (Amaral Mendes 2002). Current thinking suggests that chemicals that interfere with steroid action/production may be of more concern to reproductive health. Two examples of this are the effects of tributyltin (TBT) on marine gastropod populations and the effects of phthalates on laboratory animals. TBT was used in antifouling paints applied to boat hulls. It was subsequently linked to the appearance of 'imposex' (the growth of a penis and vas deferens in the female) in marine snails (Bryan et al. 1986). In female gastropods the growth of the male sex organs can be stimulated by testosterone, and studies have illustrated that TBT increases testosterone levels by inhibiting the enzyme aromatase which converts testosterone to oestradiol (IPCS 2002). Certain phthalate esters (ubiquitously used chemicals in manufacturing) have recently been shown to disrupt male reproductive tract organogenesis when administered to rats during pregnancy. One mechanism by which this occurs is via a large reduction in fetal testosterone synthesis and subsequently androgen levels (Mylchreest et al. 1999, Parks et al. 2000). This reduction in testosterone levels has consequences for the virilization of the male reproductive tract and will be described in more detail later. Although there are cases where single agents have been shown to be the causative chemical (e.g. TBT), it is also important to consider that we are not exposed to single agents in the environment but to a complex mixture of substances. There is currently no real understanding of what the effects of exposure to this mixture are, or whether it poses a real risk to human health. This review will focus on environmental chemicals that have the potential to affect androgen synthesis or action, in particular phthalates, and will make an effort to link the experimental data to issues concerning male reproductive health concerns.

\section{Problems with male reproductive health}

\section{Semen quality}

Carlsen et al. (1992) published a provocative study which suggested that human semen quality had declined by $\sim 50 \%$ from 1930 to 1991 . Many subsequent studies criticized or re-analysed the original meta-analysis but the trends and conclusions have been reaffirmed (Swan et al. 1997, 2000, Skakkebaek et al. 2001). The analysis of historical data suggests that the decrease in sperm quality is a birth cohort effect, with later year of birth being linked to poor semen quality i.e. the younger generation have poorer semen quality than the older generation (Irvine 1994). One of the major flaws in most studies on sperm counts is their reliance on historical data sets (retrospective studies) where different methodologies etc., may have been employed. These and other issues lead to uncertainty over the quality of the data and, therefore, doubt over the conclusions. To overcome these issues, large scale, multinational, prospective studies, using standardised methodologies are ongoing. Initial results from prospective European studies have shown regional differences in semen quality between Copenhagen, Denmark; Paris, France; Edinburgh, Scotland; and Turku, Finland. The median sperm concentrations were $61 \times 10^{6} / \mathrm{ml}$, $74 \times 10^{6} / \mathrm{ml}, \quad 77 \times 10^{6} / \mathrm{ml}$ and $82 \times 10^{6} / \mathrm{ml}$ respectively (Jorgensen et al. 2001). Recent studies published from the USA, which have used identical methodologies to the European-based studies, have also reported geographical differences in semen quality (Swan et al. 2003a). The mean sperm count was significantly lower in Columbia, Missouri $\left(58.7 \times 10^{6} / \mathrm{ml}\right)$ when compared with New York, New York $\left(102.9 \times 10^{6} / \mathrm{ml}\right)$; Minneapolis, Minnesota $\left(98.6 \times 10^{6} / \mathrm{ml}\right)$; or Los Angeles, California $\left(80 \times 10^{6} / \mathrm{ml}\right)$ (Swan et al. 2003a). Swan et al. (2003b) also compared the levels of urinary metabolites of several pesticides currently used in agriculture in men from Missouri (rural area) and Minnesota (urban area), and found an increase in pesticide levels in the samples from Missouri (Swan et al. 2003 b). A statistical correlation between poor semen quality and high levels of alachlor, diazinon, atrazine, metolachlor and 2,4-D (2,4-dichlorophenoxyacetic acid) was observed which suggest that pesticide residues may be a factor in the observed decrease in semen quality observed between rural and urban areas in the USA (Swan et al. 2003a).

In general, the reasons for these wide geographical variations in semen quality are not understood, but over time, the data from ongoing prospective studies will provide a resource to establish whether a decreasing trend in sperm counts exists. However, a more relevant question is 'what is the biological consequence of a reduction in semen quality?' A recent study of young Danish men attending medical examinations for compulsory military service between 1996-1998, found a high proportion to have suboptimal semen quality (Andersen et al. 2000). The mean sperm concentration was $57.4 \times 10^{6} / \mathrm{ml}$. However, $48 \%$ of men had sperm concentrations below $40 \times 10^{6} / \mathrm{ml}$ and $25 \%$ of men had sperm counts $<20 \times 10^{6} / \mathrm{ml}$. These cutoffs are relevant as sperm concentrations below $40 \times 10^{6} / \mathrm{ml}$ have been associated with decreased fecundity and an increased time to pregnancy (Bonde et al. 1998), whereas sperm concentrations below $20 \times 10^{6} / \mathrm{ml}$ are considered abnormal according to World Health Organization guidelines (World Health Organization 1992). This leaves an as yet unanswered question as to whether the cohort of young men with sub-optimal semen parameters will consequently have decreased fecundity/ fertility.

\section{Testicular cancer}

Testicular cancer is often quoted as the commonest cancer of young men. The secular trends across Europe and the 
United States show that it is increasing in incidence in Caucasian men (Adami et al. 1994, Bergstrom et al. 1996, SEER 2003). There is widespread geographical variation and the incidence of testicular cancer can vary up to 10-fold between countries. In Denmark in 1980, the age standardised incidence rate per 100000 population was $7.8 \%$ whereas in Lithuania it was $0.9 \%$, although in all countries where registry data has been analysed there was an annual increase of $2.3-3.4 \%$ (Adami et al. 1994). The increase in testicular cancer has been linked to a birth cohort effect, suggesting that factors affecting in utero development may be important (Bergstrom et al. 1996). Testicular germ cell cancer arises from cells which have similar characteristics to fetal germ-cells, these pre-malignant cells are termed carcinoma-in situ (CIS) cells (Rajpert-De Meyts et al. 2003). How these cells persist during development and what causes them to proliferate after puberty is not well understood, although it is thought that the factors that promote normal germ cell division may also be important in promoting CIS proliferation. Abnormal intrauterine hormone levels i.e. decreased androgen and/or increased oestrogen levels are believed to be important in the occurrence of testicular cancer (Sharpe \& Skakkebaek 1993). Similarly, decreased androgen and/or increased oestrogen levels have also been implicated in the occurrence of cryptorchidism, hypospadias and low sperm counts (Sharpe \& Skakkebaek 1993).

\section{Congenital abnormalities (cryptorchidism and hypospadias)}

Cryptorchidism and hypospadias are abnormalities normally detected at birth (congenital abnormalities). Cryptorchidism occurs when the testis does not descend into the scrotal sac; this is generally unilateral but can be bilateral. Hypospadias is a developmental abnormality of the penis in which the urethral opening is not located at the tip of the glans penis but can occur anywhere along the shaft. Determining whether there is a real increase in hypospadias and/or cryptorchidism is confounded by changes in diagnostic criteria and recording practices which make the registry data unreliable (Toppari et al. 1996, Paulozzi, 1999, Pierik et al. 2002). Despite this, cryptorchidism is the most common congenital abnormality of the newborn (2-4\% incidence) and trends for hypospadias suggest a progressive increase; based on registry data, hypospadias is the second most common $(0.3-0.7 \%$ at birth) congenital malformation (Sharpe 2003). Prospective studies are underway, which employ standardised diagnostic criteria, to collect robust data about the current incidence of cryptorchidism and hypospadias. This will allow the monitoring of future trends and allow international comparisons on the incidences of these disorders. Exposure assessment of adipose tissue (from boys undergoing correction for cryptorchidism) for selected organochlorine compounds has revealed a significant increase in heptachloroepoxide and hexachlorobenzene residues when compared with adipose tissue from children undergoing surgery for other reasons (Hosie et al. 2000). This study focussed on oestrogenic compounds and it would be interesting to know if any differences in chemical residues would be observed if anti-androgenic chemicals were assessed in a similar study.

\section{Is there a link between these male reproductive health issues?}

The strongest evidence suggesting a link between these male reproductive tract disorders, aside from the (largely imperfect) data which suggests they are all increasing in incidence, is the fact that epidemiologically the occurrence of one disorder is a risk factor for the occurrence of another (Skakkebaek et al. 2001, Sharpe 2003). This has led to the proposal that low sperm counts, hypospadias, cryptorchidism and testicular germ cell cancer are interrelated disorders comprising a 'testicular dysgenesis syndrome' (TDS; see Fig. 1) (Skakkebaek et al. 2001, Sharpe 2003). The disorders that comprise TDS all have their roots in fetal development, suggesting that a possible causal link lies in abnormal hormone synthesis or action during reproductive tract development. From the historical literature, it is well known that the administration of diethylstilboestrol (DES; a potent synthetic oestrogen) to pregnant humans and rodents causes reproductive tract abnormalities in the offspring (Stillman 1982). In male rodents, neonatal administration of DES induces a reduction in the number of Sertoli cells (the major somatic cell type which supports spermatogenesis) (Sharpe et al. 2003). There is also data suggesting DES administration to humans induces an increase in the incidence of cryptorchidism, although it is less certain whether hypospadias and testicular cancer show any significant increase (Stillman 1982). DES only induces male reproductive tract abnormalities after administration at very high doses, which are probably not relevant to environmental considerations. However, what is of more concern is that, when administered at high doses, DES and other potent oestrogens are capable of reducing androgen levels and expression of the androgen receptor protein relative to control rats (McKinnell et al. 2001, Rivas et al. 2002, 2003). This raises the important question of whether some of the genital tract abnormalities that arise from in utero administration of potent oestrogens are caused by lowered androgen levels and/or action.

\section{The role of androgens in male reproductive tract development}

Male reproductive tract development is a dynamic process requiring the interaction of many factors and hormones. One of the major factors essential for the development of the male internal and external male reproductive tract are 


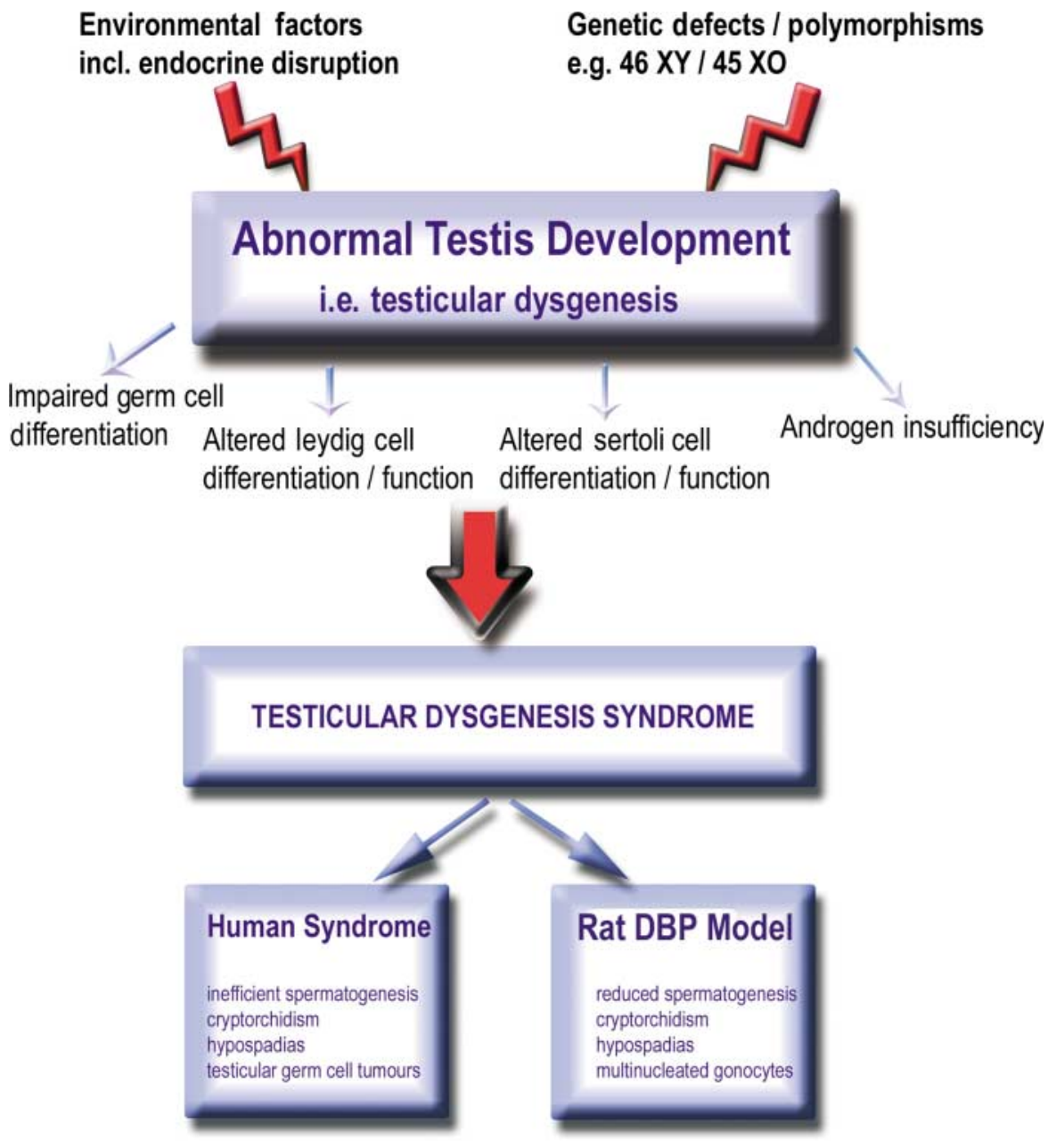

Figure 1 Schematic representation of the potential pathogenic links between testis development and the clinical manifestations of testicular dysgenesis syndrome (TDS). The similarities in the pathologies induced by in utero dibutyl phthalate (DBP) administration and human TDS are compared. the androgens, testosterone and dihydrotestosterone (DHT) (Wilson 1978). Androgens are produced by the testes during fetal and neonatal development and are essential for the maintenance of the Wolffian duct that differentiates into the epididymis, vas deferens and the seminal vesicles. The masculinization of these reproductive structures is mediated by testosterone. The masculinization of the external genitalia and prostate is largely mediated by DHT which is a more potent metabolite of testosterone and is produced by the action of the enzyme $5 \alpha$-reductase.

The central role of androgens in driving these developmental processes illustrates why chemicals that can interfere with the synthesis or action of androgens can have deleterious consequences for the developing male genital tract. Administration of the anti-androgen, flutamide (an androgen receptor antagonist), during male reproductive tract development resulted in abnormalities in the formation of the external genitalia - hypospadias and cryptorchidism; internally, agenesis of the epididymis, vas deferens and prostate (Mylchreest et al. 1999). Within the testis, degeneration of the seminiferous epithelium and Leydig cell hyperplasia were common (although this may be a consequence of the cryptorchidism rather than an anti-androgenic effect). The male pups also displayed retained thoracic nipples and a reduced anogenital distance (feminised) which are both indicative of reduced androgen action in fetal life (Mylchreest et al. 1999). In summary, both testosterone- and DHT-mediated male reproductive tract development is impaired by flutamide when administered over the period of reproductive tract differentiation.

\section{Anti-androgenic compounds in the environment}

There are a number of commonly used environmental chemicals that have been identified as having anti-androgenic properties. These chemicals have been administered to pregnant rodents during the period of reproductive tract development. When the male pups were examined, they displayed many of the abnormalities associated with flutamide administration. Some chemicals (vinclozolin, procymidone, linuron, $p, p^{\prime}$ DDE (1,1,1-dichloro-2,2-bis(pchlorophenyl)ethane) act as androgen receptor antagonists, others (phthalate esters) reduce androgen synthesis, but it is likely that other modes of action are also involved 
in the toxicity induced by these compounds (Gray et al. 2001). There are major problems in comparing the published studies of the effects of anti-androgenic compounds. The severity of the observed effects can be altered by the strain of rat used in the study, the duration and timing of administration of the test compound and the dose of the compound. This makes it very difficult to compare the extent of the effects observed between laboratories as in most cases one or more of these factors has changed. The standardization of a test protocol is required to allow a comparison of the in utero reproductive toxicity of these compounds.

The key question remains - are the environmental levels of these compounds sufficient to induce reproductive tract abnormalities in mammals? This is not an easy question to answer. It will involve the study of the effects of multicomponent mixtures of compounds to determine the effects on mammalian reproduction. The study of mixture effects in the endocrine disruption field is in its infancy. However, in vitro studies of the effects of xenoestrogen mixtures have been performed using the yeast oestrogen screen (YES) assay, which quantifies oestrogen receptor activation, and in the E-screen assay, which analyses cell proliferation as an endpoint of oestrogen action (Payne et al. 2000, Rajapakse et al. 2002, Silva et al. 2002). These studies have combined compounds such as PCBs (polychlorinated biphenols), genistein, bisphenol $\mathrm{A}$ and $o, p^{\prime}$-DDT (1,1,1-trichloro $o$-2,2-bis(p-chlorophenyl)ethane) and using pharmacological prediction models based on the dose-response curves of the single agents, predicted the effects of the combined mixture. These studies show that the combined effect of mixtures of xenoestrogens is 'additive' and generally follows the concept of concentration addition (Payne et al. 2000, Rajapakse et al. 2002, Silva et al. 2002). In these experiments, 8-11 xenoestrogens were administered at concentrations below their no observable effect concentration (NOEC), and significant oestrogenic responses were observed. It remains to be seen whether the administration of environmentally relevant concentrations of EDC mixtures will be sufficient to induce reproductive tract effects in vivo. An in vivo study assessing the effects of simultaneously administering vinclozolin and procymidone to rodents has suggested an additive response (Nellemann et al. 2003). However, the 'mixtures issue' is an important consideration in risk assessment strategies, as the data from the in vitro assays illustrate that mixture effects do occur and that studying the action of single compounds is not sufficient to assess risk. Whether in vitro assays are a good model on which to base human risk assessment is a separate issue, but in vivo studies with multi-component mixtures have to be performed to determine whether the 'mixtures issue' is relevant to human health considerations.

The following sections provide information on a few well-characterised examples of anti-androgenic compounds (vinclozolin, linuron, $p, p^{\prime} \mathrm{DDE}$ and phthalates). These have been selected to show how environmental compounds with the potential to inhibit the action of the androgen receptor or testosterone synthesis can lead to male reproductive tract abnormalities when administered at high doses to rats.

\section{Vinclozolin}

Vinclozolin is a dicarboximide fungicide that has two active metabolites, M1 and M2, which have anti-androgenic properties. In vivo and in vitro experiments demonstrate that these compounds act as potent androgen receptor antagonists, and administration to pregnant rats results in abnormalities of androgen-regulated sexual differentiation similar to those induced by flutamide, e.g. reduced anogenital distance, nipple retention, hypospadias, undescended testes and small or absent accessory glands (Gray et al. 2001). Studies have tried to define the 'sensitive window' for exposure to vinclozolin, and have determined that administration to pregnant rats during gestational day (GD) 14-19 induced reproductive tract malformations, with treatment over GD16-17 causing the most severe malformations (Wolf et al. 2000). This illustrates that the whole period of male reproductive tract differentiation is sensitive to the effects of anti-androgens.

\section{Linuron}

Linuron is a urea-based herbicide which acts as a weak androgen receptor antagonist in vitro and in vivo, and disrupts androgen-dependent male reproductive tract development after gestational exposure (Gray et al. 2001). When administered to pregnant rats (GD14-18; $100 \mathrm{mg} /$ $\mathrm{kg} /$ day) the male pups displayed a reduced anogenital distance and retention of areolas (Gray et al. 1999). Linuron failed to induce either hypospadias or undescended testes, suggesting that linuron affects testosteronebut not DHT-mediated development, though how this occurs is not known (Mclntyre et al. 2002a,b).

\section{$\mathrm{p}, \mathrm{p}^{\prime} D D E$}

The persistent pesticide, DDT, is broken down in the environment, and one of its metabolites is $p, p^{\prime}-D D E$, which has been shown to act as an androgen receptor antagonist both in vivo and in vitro (Kelce et al. 1995). Studies in which $p, p^{\prime}$-DDE was administered to rats during development (GD14-18; $100 \mathrm{mg} / \mathrm{kg} /$ day) affected androgendependent aspects of male development such that it reduced anogenital distance, caused nipple retention and, depending on the rat strain, induced hypospadias (You et al. 1998). Another DDT derivative, methoxychlor and its metabolites, have been shown to interact with both oestrogen receptors and the androgen receptor (AR). The methoxychlor metabolite, 1,1-Trichloro-2,2-bis(4 hydroxyphenyl) ethane, is an oestrogen receptor (ER)- $\alpha$ agonist, an ER- $\beta$ antagonist and an AR antagonist (see Gray et al. 2001). This illustrates that chemicals may act by more than one mechanism to induce effects on the exposed population. 
These examples serve to illustrate that in rodents the whole period of reproductive tract development is sensitive to the effects of anti-androgens. Even chemicals with the same supposed mechanism of action (i.e. androgen receptor antagonists) can induce different effects after exposure. For example, in utero treatment with linuron has effects on testosterone-mediated development whereas vinclozolin affects both testosterone and DHT target tissues. It is important to remember that many of these chemicals may turn out to be 'promiscuous' in that they will have more than one mechanism of action e.g. HPTE, so care must be taken when 'labelling' chemicals 'antiandrogens', 'oestrogens' or 'anti-oestrogens'.

\section{Phthalates}

For decades there has been concern about the reproductive toxicity of certain phthalate esters. Phthalates are used extensively in manufacturing and cosmetics production. Within rats they are lipophilic but, unlike other compounds such as DDT, they do not bioaccumulate although this may not be the case for all species. The parent phthalate is rapidly metabolised to its monoester (the active metabolite), glucuronidated and excreted. The toxicological literature on phthalates up until 2000 has been thoroughly reviewed by the first expert panel convened by the National Toxicology Program's Centre for the Evaluation of Risks to Human Reproduction (CERHR), and the interested reader is directed to this (Kavlock et al. $2002 a, b, c, d)$. The analysis of seven urinary phthalate metabolites from a reference population in the USA found the highest metabolites reflected exposure to diethyl phthalate, dibutyl phthalate (DBP) and benzylbutyl phthalate (Blount et al. 2000). These phthalate esters are used extensively in the production of perfume, nail varnish, hairsprays and other personal/cosmetic uses, suggesting that inhalation and dermal exposure may be important routes of exposure. Phthalates are known reproductive and developmental toxicants and the study by Blount et al. (2000) illustrated that women of reproductive age had significantly higher urinary levels of monobutyl phthalate (the metabolite of DBP) than the rest of the reference population (Blount et al. 2000).

Phthalates are a family of compounds and only a few induce male reproductive tract abnormalities. Gray et al. (2000) compared the ability of six phthalate esters (diethylhexyl phthalate, DEHP; benzylbutyl phthalate, BBP; diisononyl phthalate, DINP; dimethyl phthalate, DMP; diethyl phthalate, DEP; dioctyl terephthalate, DOTP; all administered at $750 \mathrm{mg} / \mathrm{kg}$ body weight from GD14 to post-natal day (PND) 3) to induce malformations of the reproductive tract (Gray et al. 2000). This study assessed changes in many androgenic endpoints and found that only DEHP, BBP and to a lesser degree DINP induced alterations in all aspects of androgen-regulated male reproductive endpoints (summarised in Table 1). Although this study did not include DBP there are reports showing that similar effects are produced after in utero exposure to this ester (Mylchreest \& Foster 2000, Mylchreest et al. 2002). The period of male reproductive tract development has been demonstrated to be the most sensitive to disruption by phthalates and the types of malformations produced are not dissimilar to those being associated with human TDS. This area of the review will largely focus on the effects of phthalates on testicular development.

\section{Effects of phthalates on testis development}

Initial reports on the effects of phthalates on male reproductive tract development focussed on the gross changes such as reduced anogenital distance, hypospadias, malformed epididymis and, in later studies, nipple retention (Mylchreest et al. 1998, 1999, Mylchreest \& Foster 2000, Mylchreest et al. 2000, 2002). Only a few studies

Table 1 Summarised alterations in androgen-mediated endpoints affected by in utero administration of phthalate esters to rats ( $750 \mathrm{mg} / \mathrm{kg}$ from gestation day $14-$ postnatal day 3 ).

\begin{tabular}{|c|c|c|c|c|c|}
\hline Affected endpoint & Androgen control $^{+}$ & Control & DEHP & BBP & DINP \\
\hline Neonatal anogenital distance (mm) & $\mathrm{DHT}$ & $3.42 \pm 0.08$ & $2.41 \pm 0.08 * *$ & $2.53 \pm 0.09 * *$ & $3.30 \pm 0.10$ \\
\hline Areolas in infant males $(\%)$ & $\mathrm{DHT}$ & 0.0 & $86.9 \pm 5.0 *$ & $70.0 \pm 11.0 *$ & $22.4 \pm 8.9 *$ \\
\hline Nipple retention $(\%)$ & $\mathrm{DHT}$ & 0.0 & 76 & 71 & 4 \\
\hline Cleft phallus (\%) & $\mathrm{DHT}$ & 0.0 & 44 & 42 & 0 \\
\hline Hypospadias (\%) & $\mathrm{DHT}$ & 0.0 & 42 & 29 & 0 \\
\hline Vaginal pouch $(\%)$ & $\mathrm{DHT}$ & 0.0 & 33 & 16 & 0 \\
\hline VP agenesis (\%) & $\mathrm{DHT}$ & 0.0 & 29 & 27 & 0 \\
\hline SV agenesis (\%) & $\mathrm{T}$ & 0.0 & 40 & 38 & 0 \\
\hline Epididymal agenesis (\%) & $\mathrm{T}$ & 0.0 & 69 & 67 & 2 \\
\hline Undescended testes (\%) & T/INSL3/AMH & 0.0 & 24 & 22 & 0 \\
\hline Abnormal gubernaculum (\%) & $\mathrm{T}$ & 0.0 & 52 & 57 & 2 \\
\hline Incomplete preputial separation (\%) & Pubertal landmark & 0.0 & $34 *$ & $19.6 *$ & 0 \\
\hline
\end{tabular}

${ }^{+}$Androgen control, the major androgen driving development of each endpoint.

DEHP, diethylhexyl phthalate; BBP, benzylbutyl phthalate; DINP, diisononyl phthalate. VP, ventral prostate; SV, seminal vesicle; DHT, dihydrotestosterone; T, testosterone; INSL3, insulin-like growth factor-3; AMH, anti-Müllerian hormone.

$* P<0.01, * * P<0.001$ compared with respective control value.

Data summarised from Gray et al. (2000). 
give a more detailed account of the histological changes observed in the testis after in utero phthalate exposure and demonstrate that the fetal testis is directly affected by phthalates during fetal and neonatal testis differentiation (Parks et al. 2000, Mylchreest et al. 2002, Fisher et al. 2003). Some of these alterations are permanent and affect the function of the testis in adult life and are similar to the histological changes which are now being shown in patients with TDS (Skakkebaek et al. 2003, Hoei-Hansen et al. 2003). To understand the possible mechanisms by which phthalate exposure could disrupt testis development, a brief account of testis formation is given below.

\section{Testis development}

Testis formation is driven by activation of the sex-determining region of the $Y$ chromosome (SRY) leading to the differentiation of Sertoli cells (Koopman et al. 1990). The formation of Sertoli cells fixes the fate of the indifferent gonad, directing its progression along testis development. The Sertoli cell is the driving force of testis development, orchestrating the dynamic processes of cell movement, organisation and differentiation of themselves and all the other cell types within the testis (see Fig. 2) (Capel 2000, Koopman 2001).

The Sertoli cells form clusters around the primordial germ cells, enclosing them in the seminiferous cords. The Sertoli cells are believed to signal the overlying mesonephros to allow cell migration into the cords, allowing further cord development and expansion of the cell population (Koopman 2001). The seminiferous cords become surrounded by a basal lamina that is formed via an interaction of the Sertoli cells with the peritubular myoid cells. The differentiation of Leydig cells is also induced by the Sertoli cell (Koopman 2001) and is essential for the production of testosterone and the masculinization of the male reproductive tract. The regression of the Müllerian duct (female anlage) is also induced by the Sertoli cells via the secretion of Müllerian inhibiting substance (MIS), also termed anti-Müllerian hormone (AMH). Later during testis development, the Sertoli cells secrete an as yet unidentified inhibiting substance that prevents the germ cells from entering meiosis and blocks them from entering the oogenic pathway. There is a vast array of genes/signals involved in testis organogenesis that still have to be unravelled. The interested reader is directed to two recent reviews (Capel 2000, Koopman 2001).

Indirect evidence for altered Sertoli cell function after in utero phthalate administration during testis development has been obtained. Indeed, all the abnormalities described below might stem from abnormal Sertoli cell function (see Fig. 2). At GD19 an abnormal interaction between the Sertoli cells and gonocytes has been reported after in utero administration of DBP, which suggested a lack of Sertoli cell-germ cell interaction/adhesion (Fisher et al. 2003). An analogous phenomenon was described during the in vitro co-culture of gonocytes and Sertoli cells. After the administration of DEHP, gonocytes were observed to detach from the Sertoli cells, again suggesting problems with cell adhesion ( $\mathrm{Li}$ et al. 1998). Data from the postnatal testis illustrate evidence of abnormal Sertoli cell maturation as shown by the lack of expression of the cell cycle marker p2 $7^{\text {kip }}$ in Sertoli cells in dysgenetic areas or Sertoli-cell-only tubules (SCO) (Fisher et al. 2003).

\section{Leydig cells}

The number and distribution of fetal Leydig cells is altered after in utero exposure to DBP or DEHP (Parks et al. 2000, Mylchreest et al. 2002, Fisher et al. 2003). These studies report that at around GD16 there was a focal hyperplasia within the interstitium, and immunolocalisation with the steroidogenic enzyme 3-beta hydroxysteroid dehydrogenase $(3 \beta \mathrm{HSB})$ indicated that the majority of these cells were

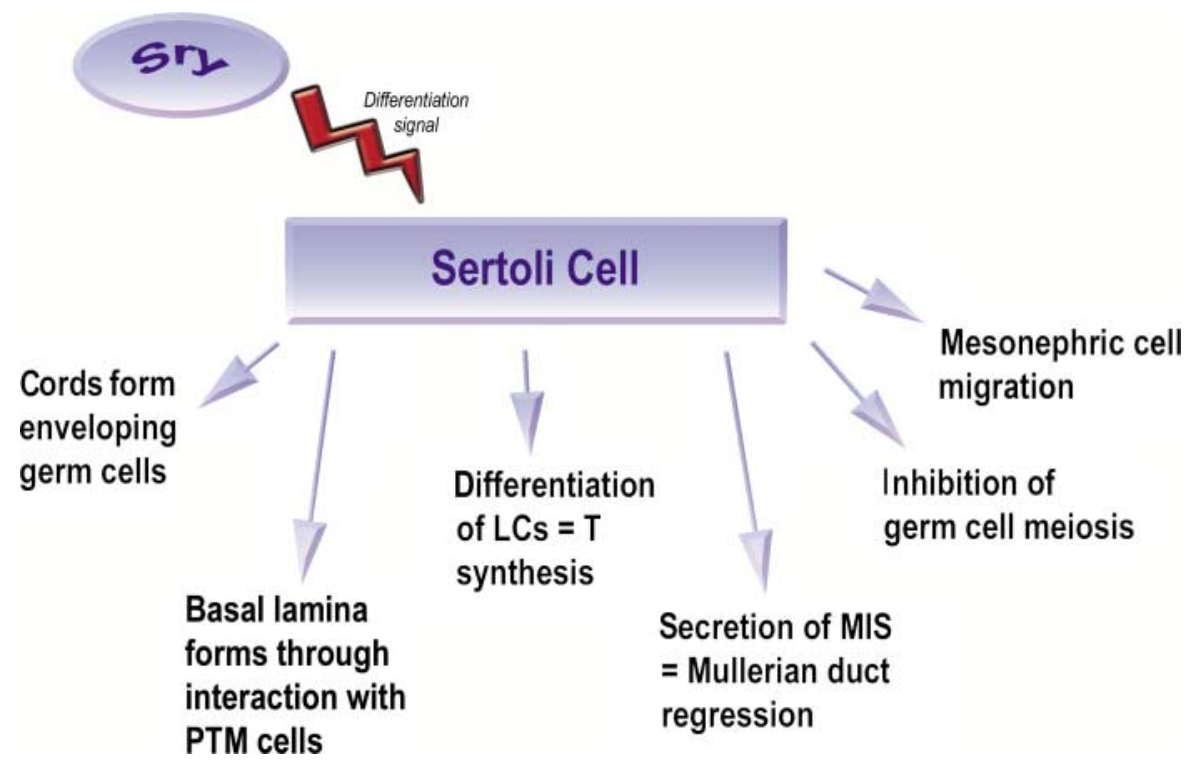

Figure 2 Schematic representation of the central role of the Sertoli cell in driving the process of testis differentiation. Sry, sex-determining region of the $\mathrm{Y}$ chromosome; PTM cells, peritubular myoid cells; LCs, Leydig cells; T, testosterone; MIS, Müllerian inhibiting substance. 
fetal Leydig cells. Postnatally, Leydig cell hyperplasia was still evident, particularly in the vicinity of dysgenetic areas. Some of these areas are so large that they have been classified as Leydig cell adenomas (Mylchreest et al. 1998, 1999, 2000). Leydig cell hyperplasia ('micronodules') is common in testicular biopsies from men with impaired spermatogenesis and patients with testicular cancer suggesting this is a feature of TDS (Hoei-Hansen et al. 2003, Holm et al. 2003).

\section{Testosterone production}

The production of testosterone is critical for the normal masculinization of the male reproductive tract, as already discussed. It has been shown that DBP and DEHP are both capable of inhibiting the production of testosterone by the fetal testis (Parks et al. 2000, Mylchreest et al. 2002, Fisher et al. 2003). Testosterone synthesis by the fetal testis is first detectable by GD15, reaches a peak at around GD18/19, and remains high until birth. However, phthalate treatment induces a $60-85 \%$ reduction in testosterone synthesis during this critical developmental window, reducing testosterone levels to a similar level to those found in females (Parks et al. 2000). This reduction in testosterone is a factor in the occurrence of hypospadias and cryptorchidism observed after phthalate treatment.

\section{Peritubular myoid cells/seminiferous cord formation}

Abnormal seminiferous cord formation has been described after in utero DBP administration (Fisher et al. 2003). Peritubular myoid cells lie on the outer circumference of the seminiferous cord and act as a visual boundary to separate the cords from the interstitium. At postnatal day 4, abnormal seminiferous cord formation was evident with large, discrete areas of the testis displaying malformed cords that contained Sertoli cells and gonocytes. These abnormal foci were a permanent feature of the testis that became more discrete as the testis enlarged during postnatal development. Morphologically malformed seminiferous tubules have been observed in human biopsies from the contra-lateral testis of testis cancer patients suggesting this may be a feature of TDS (Hoei-Hansen et al. 2003).

\section{Gonocytes}

Aside from the apparent cell adhesion problems between the Sertoli cells and gonocytes described above, abnormal germ cell mitosis has been reported as observed by the appearance of multinucleated gonocytes (MNGs) in the fetal testes of DBP- or DEHP-exposed foetuses (Gray et al. 2000, Parks et al. 2000, Mylchreest et al. 2002, Fisher et al. 2003). MNG arise at $\sim$ GD19 and are observed until $\sim$ PND10. Their disappearance coincides with the apoptosis of gonocytes that have not made contact with the basement membrane of the seminiferous cord and

Reproduction (2004) 127 305-315 differentiated into spermatogonia. Multinucleated spermatogonia have been found in human biopsy samples from cryptorchid boys and may be associated with the occurence of testicular cancer (Cortes et al. 2003).

\section{Parallels between human testicular dysgenesis syndrome and rodent in utero exposure to DBP}

The spectrum of disorders induced by phthalate administration to rats closely parallels those observed in human TDS (with the exception of germ cell cancer). This has led researchers to suggest that in utero treatment of rodents with certain phthalates could be used as a model to dissect out possible mechanisms occurring in human TDS, for which there is currently no suitable model (Fig. 1). This is not to suggest that phthalate exposure causes TDS in humans, merely that the administration of very high doses of DBP to pregnant rats induces a TDS-like syndrome in the male offspring that shows many analogous features to human TDS. It is plausible, given how highly conserved the pathways of fetal development are, that phthalate administration may disrupt some common mechanistic pathways which if altered in humans could be helpful in determining the pathogenesis of human TDS. In both the human syndrome and the rodent model, abnormal testicular development or dysgenesis is evident by the abnormal organisation of these tissues. In humans, histological evidence of testicular dysgenesis (immature seminiferous tubules with undifferentiated Sertoli cells, microcalcifications and SCO tubules, Leydig cell hyperplasia, morphologically distorted tubules and the presence of CIS cells) have been found in biopsies of the contra-lateral testes of testicular germ cell cancer patients and in biopsies from patients with infertility, hypospadias and cryptorchidism (Skakkebaek et al. 2003, Hoei-Hansen et al. 2003, Holm et al. 2003). These studies support the hypothesis that all of these disorders (low sperm counts, cryptorchidism, hypospadias and testicular cancer) are associated with TDS. The in utero administration of DBP to rodents during the sensitive period of tissue morphogenesis permanently alters the testis and produces foci of testicular dysgenesis (immature seminiferous tubules with undifferentiated Sertoli cells, SCO tubules, Leydig cell hyperplasia, morphologically distorted tubules and the presence of abnormal germ cells) which persist in the adult animal (Fisher et al. 2003). The downstream consequences of altered Sertoli cell (and subsequently Leydig cell) function (as illustrated in Fig. 2) may be a key cause of many of the observed changes in both human TDS and the rat TDS-like model due to the central role of this cell type in driving testis morphogenesis in both rodents and humans.

\section{Conclusions}

Since the initial concerns arose about environmental chemicals and falling sperm counts, there has been an 
explosion of research in this area. The initial 'environmental oestrogen' hypothesis has been superseded by a more refined definition of EDCs. It is now accepted that there are a plethora of ways in which chemicals can potentially act on the endocrine system. Definitive data to determine whether human male reproductive health is declining are still required however; the hypothesis of a 'testicular dysgenesis syndrome' is an important advance and may aid our understanding of the underlying aetiology of these disorders. Within the reproductive tract, the male is exquisitely vulnerable to the effects of anti-androgens during development due the reliance on the synthesis and action of androgens for the masculinization of the male reproductive tract. The ability of phthalates to suppress androgen synthesis during development and to induce testicular dysgenesis together with cryptorchidism and hypospadias has close parallels with human TDS. However, the crucial question regarding whether the level of environmental chemicals is sufficient to impact on human male reproductive health remains unanswered, although advances will be made from studying the effects of multi-component EDC mixtures in both in vitro and in vivo test systems. It remains to be seen what consequences this research will generate for human risk assessment strategies.

\section{Acknowledgements}

The author would like to thank Drs Richard Sharpe and Andreas Kortenkamp for their critical comments on this manuscript. The author is supported by grant QLK4-CT-200200603 from the European Union.

\section{References}

Adami HO, Bergstrom R, Mohner M, Zatonski W, Storm $\mathbf{H}$, Ekbom A, Tretli S, Teppo L, Ziegler H \& Rahu M 1994 Testicular cancer in nine northern European countries. International Journal of Cancer 59 33-38.

Amaral Mendes JJ 2002 The endocrine disrupters: a major medical challenge. Food and Chemical Toxicology 40 781-788.

Andersen AG, Jensen TK, Carlsen E, Jorgensen N, Andersson AM, Krarup T, Keiding N \& Skakkebaek NE 2000 High frequency of sub-optimal semen quality in an unselected population of young men. Human Reproduction 15 366-372.

Bergstrom R, Adami HO, Mohner M, Zatonski W, Storm H, Ekbom A, Tretli S, Teppo L, Akre O \& Hakulinen T 1996 Increase in testicular cancer incidence in six European countries: a birth cohort phenomenon. Journal of the National Cancer Institute $\mathbf{8 8}$ 727-733.

Blount BC, Silva MJ, Caudill SP, Needham LL, Pirkle JL, Sampson EJ, Lucier GW, Jackson RJ \& Brock JW 2000 Levels of seven urinary phthalate metabolites in a human reference population. Environmental Health Perspectives 108 979-982.

Bonde JP, Ernst E, Jensen TK, Hjollund NH, Kolstad H, Henriksen TB, Scheike T, Giwercman A, Olsen J \& Skakkebaek NE 1998 Relation between semen quality and fertility: a population-based study of 430 first-pregnancy planners. Lancet 352 1172-1177.

Bryan GW, Gibbs PE, Hummerstone LG \& Burt GR 1986 The decline of the gastropod Nucella lapillus around south-west England: evidence for the effect of tributyltin from anti-fouling paints. Journal of the Marine Biological Association of the United Kingdom $\mathbf{6 6}$ 611-640.

Capel B 2000 The battle of the sexes. Mechanisms of Development $9289-103$.

Carlsen E, Giwercman A, Keiding N \& Skakkebaek NE 1992 Evidence for decreasing quality of semen during past 50 years. British Medical Journal 305 609-613.

Cortes D, Thorup J \& Visfeldt J 2003 Multinucleated spermatogonia in cryptorchid boys: a possible association with an increased risk of testicular malignancy later in life? Acta Pathologica Microbiologica et Immunologica Scandinavica 111 25-30.

Fisher JS, Macpherson S, Marchetti N \& Sharpe RM 2003 Human 'testicular dysgenesis syndrome': a possible model using in-utero exposure of the rat to dibutyl phthalate. Human Reproduction $\mathbf{1 8}$ 1383-1394.

Gray LE Jr, Wolf C, Lambright C, Mann P, Price M, Cooper RL \& Ostby J 1999 Administration of potentially antiandrogenic pesticides (procymidone, linuron, iprodione, chlozolinate, $p, p^{\prime}$-DDE, and ketoconazole) and toxic substances (dibutyl- and diethylhexyl phthalate, PCB 169, and ethane dimethane sulphonate) during sexual differentiation produces diverse profiles of reproductive malformations in the male rat. Toxicology and Industrial Health $\mathbf{1 5}$ 94-118.

Gray LE Jr, Ostby J, Furr J, Price M, Veeramachaneni DN \& Parks L 2000 Perinatal exposure to the phthalates DEHP, BBP, and DINP, but not DEP, DMP, or DOTP, alters sexual differentiation of the male rat. Toxicological Sciences 58 350-365.

Gray LE, Ostby J, Furr J, Wolf CJ, Lambright C, Parks L, Veeramachaneni DN, Wilson V, Price $M$, Hotchkiss A, Orlando E \& Guillette L 2001 Effects of environmental antiandrogens on reproductive development in experimental animals. Human Reproduction Update 7 248-264.

Hoei-Hansen CE, Holm M, Rajpert-De Meyts E \& Skakkebaek NE 2003 Histological evidence of testicular dysgenesis in contralateral biopsies from 218 patients with testicular germ cell cancer. Journal of Pathology 200 370-374.

Holm M, Rajpert-De Meyts E, Andersson AM \& Skakkebaek NE 2003 Leydig cell micronodules are a common finding in testicular biopsies from men with impaired spermatogenesis and are associated with decreased testosterone/LH ratio. Journal of Patholology $199378-386$.

Hosie S, Loff S, Witt K, Niessen K \& Waag KL 2000 Is there a correlation between organochlorine compounds and undescended testes? European Journal of Pediatric Surgery 10 304-309.

IPCS 2002, Global Assessment of the State-of-the-Science of Endocrine Disruptors. http://ehp.niehs.nih.gov/who/preface.pdf.Eds T Damstra, S Barlow, A Bergman, R Kavlock \& G Van Der Kraak.

Irvine DS 1994 Falling sperm quality. British Medical Journal 309 476.

Jorgensen N, Andersen AG, Eustache F, Irvine DS, Suominen J, Petersen JH, Andersen AN, Auger J, Cawood EH, Horte A, Jensen TK, Jouannet P, Keiding N, Vierula M, Toppari J \& Skakkebaek NE 2001 Regional differences in semen quality in Europe. Human Reproduction 16 1012-1019.

Kavlock R, Boekelheide K, Chapin R, Cunningham M, Faustman E, Foster P, Golub M, Henderson R, Hinberg I, Little R, Seed J, Shea K, Tabacova S, Tyl R, Williams P \& Zacharewski T 2002a NTP Center for the Evaluation of Risks to Human Reproduction: Phthalates Expert Panel report on the reproductive and developmental toxicity of butyl benzyl phthalate. Reproductive Toxicology $\mathbf{1 6}$ 453-487.

Kavlock R, Boekelheide K, Chapin R, Cunningham M, Faustman E, Foster P, Golub M, Henderson R, Hinberg I, Little R, Seed J, Shea K, Tabacova S, Tyl R, Williams P \& Zacharewski T 2002b NTP Center for the Evaluation of Risks to Human Reproduction: Phthalates Expert Panel report on the reproductive and developmental toxicity of di(2-ethylhexyl) phthalate. Reproductive Toxicology 16 529-653. 
Kavlock R, Boekelheide K, Chapin R, Cunningham M, Faustman E, Foster P, Golub M, Henderson R, Hinberg I, Little R, Seed J, Shea K, Tabacova S, Tyl R, Williams P \& Zacharewski T 2002C NTP Center for the Evaluation of Risks to Human Reproduction: Phthalates Expert Panel report on the reproductive and developmental toxicity of di-isononyl phthalate. Reproductive Toxicology $\mathbf{1 6}$ 679-708.

Kavlock R, Boekelheide K, Chapin R, Cunningham M, Faustman E, Foster P, Golub M, Henderson R, Hinberg I, Little R, Seed J, Shea K, Tabacova S, Tyl R, Williams P \& Zacharewski T 2002d NTP Center for the Evaluation of Risks to Human Reproduction: Phthalates Expert Panel report on the reproductive and developmental toxicity of di-n-butyl phthalate. Reproductive Toxicology 16 $489-527$.

Kelce WR, Stone CR, Laws SC, Gray LE, Kemppainen JA \& Wilson EM 1995 Persistent DDT metabolite $p, p^{\prime}$-DDE is a potent androgen receptor antagonist. Nature 375 581-585.

Koopman P 2001 Gonad development: signals for sex. Current Biology 11 R481-R483.

Koopman P, Munsterberg A, Capel B, Vivian N \& Lovell-Badge R 1990 Expression of a candidate sex-determining gene during mouse testis differentiation. Nature 348 450-452.

Li LH, Jester WF Jr \& Orth JM 1998 Effects of relatively low levels of mono-(2-ethylhexyl) phthalate on cocultured Sertoli cells and gonocytes from neonatal rats. Toxicology and Applied Pharmacology $153258-265$.

McIntyre BS, Barlow NJ \& Foster PM 2002a Male rats exposed to linuron in utero exhibit permanent changes in anogenital distance, nipple retention, and epididymal malformations that result in subsequent testicular atrophy. Toxicological Sciences 65 62-70.

McIntyre BS, Barlow NJ, Sar M, Wallace DG \& Foster PM 2002b Effects of in utero linuron exposure on rat Wolffian duct development. Reproductive Toxicology 16 131-139.

McKinnell C, Atanassova N, Williams K, Fisher JS, Walker M, Turner KJ, Saunders TK \& Sharpe RM 2001 Suppression of androgen action and the induction of gross abnormalities of the reproductive tract in male rats treated neonatally with diethylstilbestrol. Journal of Andrology 22 323-338.

Mylchreest E \& Foster PM 2000 DBP exerts its antiandrogenic activity by indirectly interfering with androgen signaling pathways. Toxicology and Applied Pharmacology 168 174-175.

Mylchreest E, Cattley RC \& Foster PM 1998 Male reproductive tract malformations in rats following gestational and lactational exposure to di(n-butyl) phthalate: an antiandrogenic mechanism? Toxicological Sciences 43 47-60.

Mylchreest E, Sar M, Cattley RC \& Foster PM 1999 Disruption of androgen-regulated male reproductive development by di(n-butyl) phthalate during late gestation in rats is different from flutamide. Toxicology and Applied Pharmacology 156 81-95.

Mylchreest E, Wallace DG, Cattley RC \& Foster PM 2000 Dosedependent alterations in androgen-regulated male reproductive development in rats exposed to di(n-butyl) phthalate during late gestation. Toxicological Sciences 55 143-151.

Mylchreest E, Sar M, Wallace DG \& Foster PM 2002 Fetal testosterone insufficiency and abnormal proliferation of Leydig cells and gonocytes in rats exposed to di(n-butyl) phthalate. Reproductive Toxicology 16 19-28.

Nellemann C, Dalgaard M, Lam HR \& Vinggaard AM 2003 The combined effects of vinclozolin and procymidone do not deviate from expected additivity in vitro and in vivo. Toxicological Sciences 71 251-262.

Parks LG, Ostby JS, Lambright CR, Abbott BD, Klinefelter GR, Barlow NJ \& Gray LE Jr 2000 The plasticizer diethylhexyl phthalate induces malformations by decreasing fetal testosterone synthesis during sexual differentiation in the male rat. Toxicological Sciences 58 339-349.

Paulozzi LJ 1999 International trends in rates of hypospadias and cryptorchidism. Environmental Health Perspectives 107 297-302.
Payne J, Rajapakse N, Wilkins M \& Kortenkamp A 2000 Prediction and assessment of the effects of mixtures of four xenoestrogens. Environmental Health Perspectives 108 983-987.

Pierik FH, Burdorf A, Nijman JM, de Muinck Keizer-Schrama SM, Juttmann RE \& Weber RF 2002 A high hypospadias rate in The Netherlands. Human Reproduction 17 1112-1115.

Rajapakse N, Silva E \& Kortenkamp A 2002 Combining xenoestrogens at levels below individual no-observed-effect concentrations dramatically enhances steroid hormone action. Environmental Health Perspectives 110 917-921.

Rajpert-De Meyts E, Bartkova J, Samson M, Hoei-Hansen CE, Frydelund-Larsen L, Bartek J \& Skakkebaek NE 2003 The emerging phenotype of the testicular carcinoma in situ germ cell. Acta Pathologica, Microbiologica et Immunologica Scandinavica 111 267-278.

Rivas A, Fisher JS, McKinnell C, Atanassova N \& Sharpe RM 2002 Induction of reproductive tract developmental abnormalities in the male rat by lowering androgen production or action in combination with a low dose of diethylstilbestrol: evidence for importance of the androgen-estrogen balance. Endocrinology 143 4797-4808.

Rivas A, McKinnell C, Fisher JS, Atanassova N, Williams K \& Sharpe RM 2003 Neonatal coadministration of testosterone with diethylstilbestrol prevents diethylstilbestrol induction of most reproductive tract abnormalities in male rats. Journal of Andrology 24 557-567.

SEER 2003 SEER Cancer Statistics Review, 1975-2000. http://seer. cancer.gov/csr/1975_2000. Bethesda, MD: National Cancer Institute.

Sharpe RM 2003 The 'oestrogen hypothesis' - where do we stand now? International Journal of Andrology 26 2-15.

Sharpe RM \& Skakkebaek NE 1993 Are oestrogens involved in falling sperm counts and disorders of the male reproductive tract? Lancet $3411392-1395$.

Sharpe RM \& Franks S 2002 Environment, lifestyle and infertility - an inter-generational issue. Nature Cell Biology 4 (Suppl) S33-S40.

Sharpe RM, McKinnell C, Kivlin C \& Fisher JS 2003 Proliferation and functional maturation of Sertoli cells, and their relevance to disorders of testis function in adulthood. Reproduction $\mathbf{1 2 5}$ 769-784.

Silva E, Rajapakse N \& Kortenkamp A 2002 Something from 'nothing' - eight weak estrogenic chemicals combined at concentrations below NOECs produce significant mixture effects. Environmental Science and Technology 36 1751-1756.

Skakkebaek NE, Rajpert-De Meyts E \& Main KM 2001 Testicular dysgenesis syndrome: an increasingly common developmental disorder with environmental aspects. Human Reproduction $\mathbf{1 6}$ 972-978.

Skakkebaek NE, Holm M, Hoei-Hansen C, Jorgensen N \& RajpertDe Meyts E 2003 Association between testicular dysgenesis syndrome (TDS) and testicular neoplasia: evidence from 20 adult patients with signs of maldevelopment of the testis. Acta Pathologica, Microbiologica et Immunologica Scandinavica 111 1-9.

Stillman RJ 1982 In utero exposure to diethylstilbestrol: adverse effects on the reproductive tract and reproductive performance and male and female offspring. American Journal of Obstetrics and Gynecology 142 905-921.

Swan SH, Elkin EP \& Fenster L 1997 Have sperm densities declined? A reanalysis of global trend data. Environmental Health Perspectives 105 1228-1232.

Swan SH, Elkin EP \& Fenster L 2000 The question of declining sperm density revisited: an analysis of 101 studies published 1934-1996. Environmental Health Perspectives 108 961-966.

Swan SH, Brazil C, Drobnis EZ, Liu F, Kruse RL, Hatch M, Redmon JB, Wang C \& Overstreet JW 2003a Geographic differences in semen quality of fertile US males. Environmental Health Perspectives 111 414-420.

Swan SH, Kruse RL, Liu F, Barr DB, Drobnis EZ, Redmon JB, Wang C, Brazil C \& Overstreet JW 2003b Semen quality in relation to bio- 
markers of pesticide exposure. Environmental Health Perspectives 111 1478-1484.

Toppari J, Larsen JC, Christiansen P, Giwercman A, Grandjean P, Guillette LJ Jr, Jegou B, Jensen TK, Jouannet $P$, Keiding N, Leffers H, McLachlan JA, Meyer O, Muller J, Rajpert-De Meyts E, Scheike T, Sharpe R, Sumpter J \& Skakkebaek NE 1996 Male reproductive health and environmental xenoestrogens. Environmental Health Perspectives 104 (Suppl 4) 741-803.

Wilson JD 1978 Sexual differentiation. Annual Review of Physiology 40 279-306.

Wolf CJ, LeBlanc GA, Ostby JS \& Gray LE Jr 2000 Characterization of the period of sensitivity of fetal male sexual development to vinclozolin. Toxicological Sciences 55 152-161.
World Health Organization, 1992 WHO Laboratory Manual for the Examination of Human Semen and Sperm-Cervical Mucus Interaction, 3rd edn. Cambridge: Cambridge University Press.

You L, Casanova M, Archibeque-Engle S, Sar M, Fan LQ \& Heck HA 1998 Impaired male sexual development in perinatal SpragueDawley and Long-Evans hooded rats exposed in utero and lactationally to $p, p^{\prime}$-DDE. Toxicological Sciences 45 162-173.

Received 25 September 2003

First decision 24 November 2003

Accepted 8 January 2004 